\title{
Post Endodontic Restoration of Severely Decayed Primary Dentition: A Challenge to Pediatric Dental Surgeon
}

\author{
${ }^{1}$ Srinivas N CH, ${ }^{2} \mathrm{M}$ Jayanthi \\ ${ }^{1}$ Senior Lecturer, Panineeya Mahavidyalaya Institute of Dental Sciences and Research Center, Hyderabad, Andhra Pradesh, India \\ ${ }^{2}$ Professor and Head, Department of Pedodontics and Preventive Dentistry, Ragas Dental College and Hospital \\ Chennai, Tamil Nadu, India
}

Correspondence: Srinivas N CH, Senior Lecturer, Panineeya Mahavidyalaya Institute of Dental Sciences and Research Center Hyderabad, Andhra Pradesh, India, Phone: 001-9963002821, e-mail: cnudent@gmail.com, seenuchary@yahoo.com

\section{ABSTRACT}

Dental caries is the single most common chronic childhood disease. In early childhood caries, there is early pulpal involvement and gross destruction of the maxillary anterior teeth. This leads to decreased masticatory efficiency, difficulty in speech, psychological problems due to compromised esthetics, development of abnormal tongue habits and subsequent malocclusion. The restoration of severely decayed primary incisors is often a procedure that presents a special challenge to dentists, particularly in an uncooperative child. This case presents the clinical sequence of rehabilitation of upper anterior primary teeth, where endodontic treatments were done chairside followed by the construction of root post using stainless steel and the fabrication of crowns composed of resin.

Keywords: Composite resin, Rampant caries, Post, Primary anterior teeth.

\section{INTRODUCTION}

A problem commonly faced in pediatric clinics is the restoration of primary maxillary incisors severely destroyed by trauma or caries. M ost cases are observed among children with nursing bottle caries..$^{1-3}$ In early childhood caries, there is early carious involvement of the maxillary anterior teeth. ${ }^{4}$

Premature loss of carious primary incisors may affect the speech by interfering with the pronunciation of consonants and labial sounds, decreased masticatory efficiency, abnormal tongue habits and potentially subsequent malocclusion. The child may also suffer from psychological problems if esthetic demands are compromised. ${ }^{5,6}$

The esthetic restoration of severely mutilated primary anterior teeth had been a challenge for the dentist for a long time, not only because of the available material s and techniques but also because the children who require such restorations are usually among the youngest and least manageable group of patients. ${ }^{1}$

A restorative technique that is able to provide efficient, durable and functional restorations, that is simple to perform would enhance the management of patients presenting with carious maxillary primary incisors. Such a technique could help to ensure the child's cooperation and reduce the anxiety associated with restorative treatment. ${ }^{7}$

This case report describes the challenging task of treating a 4-year-old early childhood caries with mutilated maxillary incisors with composite resin using a custom-made post, made with $0.7 \mathrm{~mm}$ wire to increase the potential surface area for attachment of the restorative material and consequently increase the long-term stability of an esthetic restoration as well as other restorative procedures in the needful teeth.

\section{CASE REPORT}

A 4-year-old female patient reported to the Department of Pedodontics and Preventive Dentistry, Ragas Dental College and Hospital, Chennai, with a complaint of severely decayed teeth. The child was shy, withdrawn and uncooperative (Fig. 1).

\section{Examination and Treatment Procedure}

Intraoral examination revealed a complete set of deciduous dentition and caries involving with 51,52,61, 62, 54 and 64 (Fig. 2). All the incisors are grossly destructed, and on intraoral periapical radiograph, there is pulpal involvement of 51,61 , 52, 62. Diet analysis, counseling and oral prophylaxis were done. Fluoride application after temporization was done. Pulpectomy was done on 51, 61, 52, 62 (Fig. 3), followed by

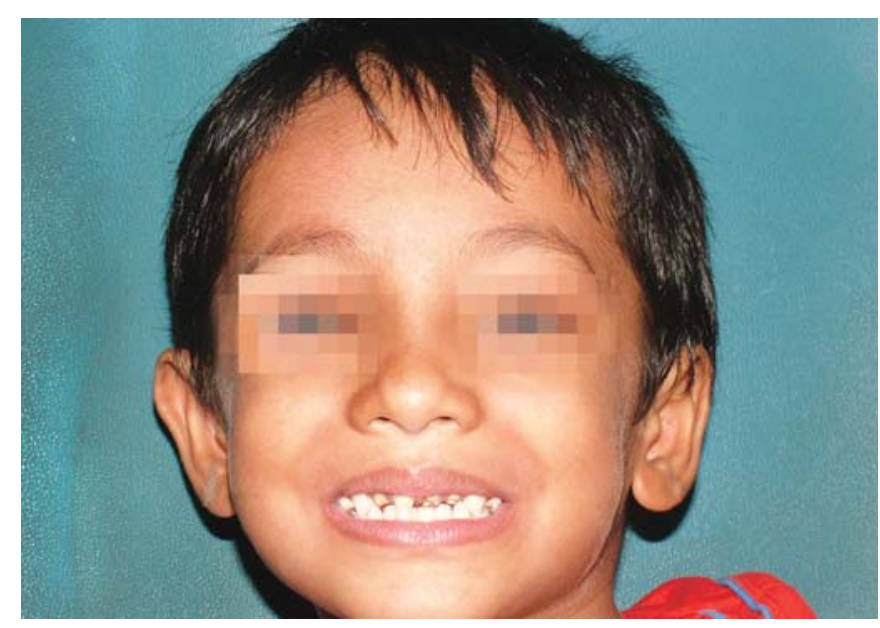

Fig. 1: Preoperative view of the uncooperative patient displaying shyness 


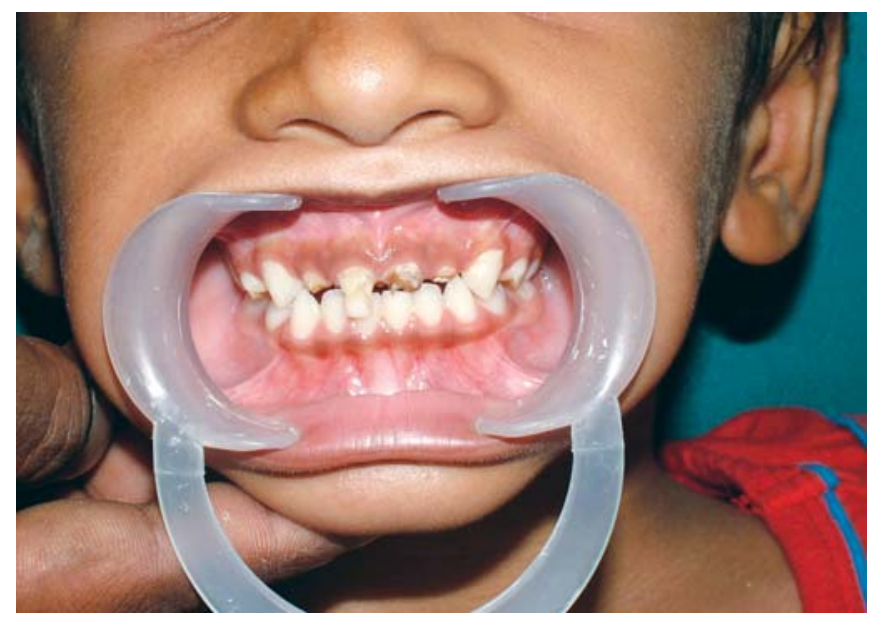

Fig. 2: Maxilla and mandible in occlusion showing grossly decayed $51,52,61,62$

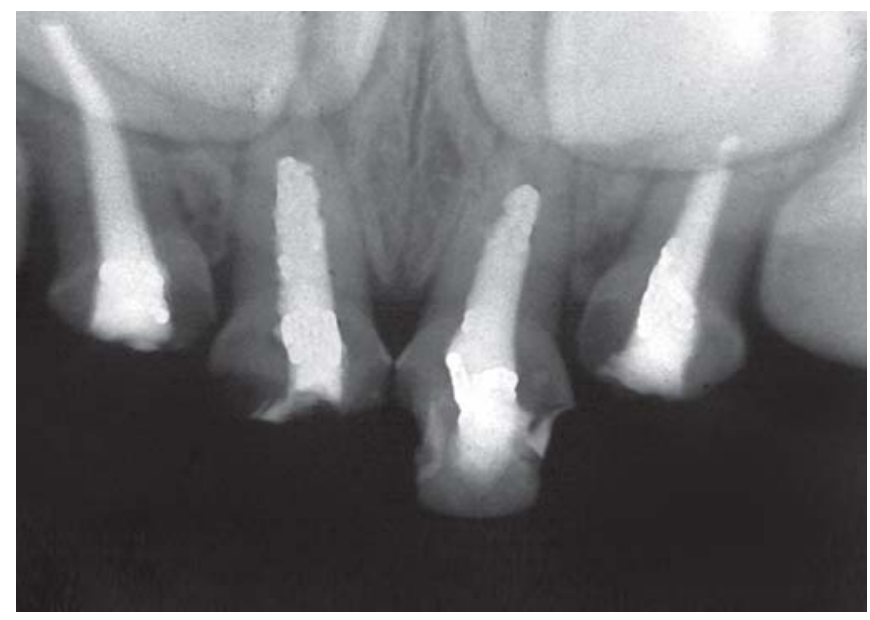

Fig. 3: IOPA showing pulpectomy done on 51, 52, 61, 62

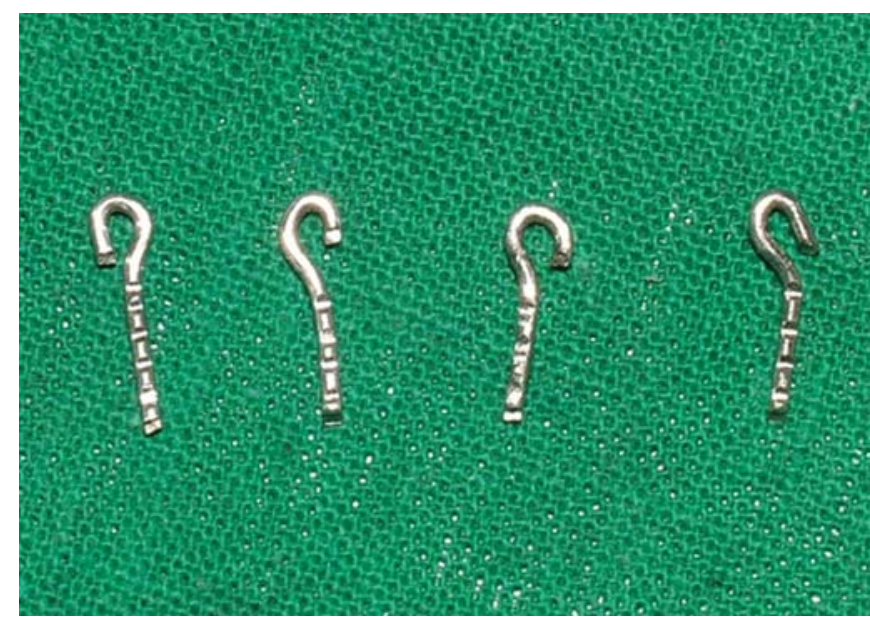

Fig. 4: Custom made half omega shape post made with $0.7 \mathrm{~mm}$ wire with serrations

custom-made half omega-shaped post made with $0.7 \mathrm{~mm}$ wire with serrations done to increase the potential surface area for attachment of the restorative material and consequently increase the long-term stability of an esthetic restoration (Figs 4 and 5 ). Glass ionomer restorations were done on 54 and 64.

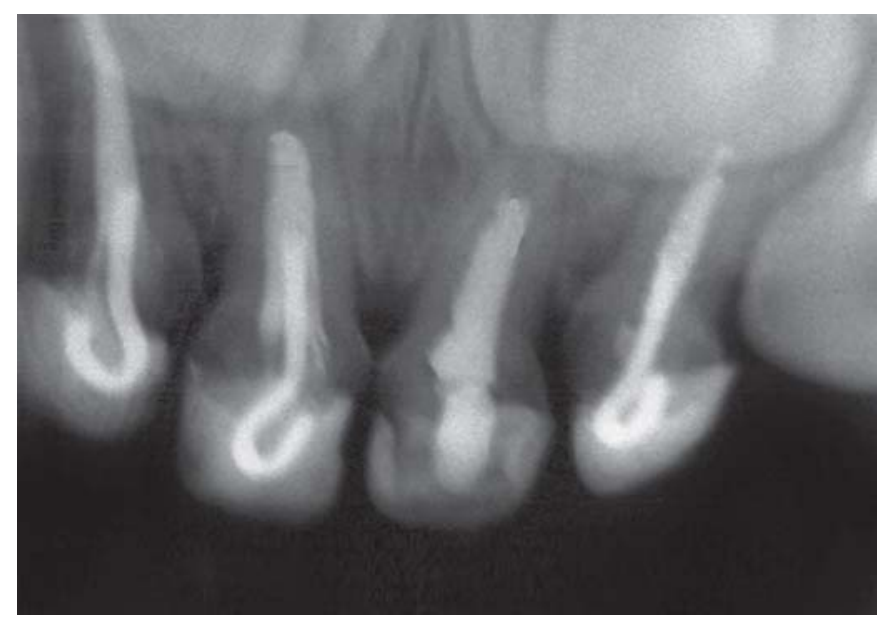

Fig. 5: IOPA showing post luted on 51, 52, 61, 62

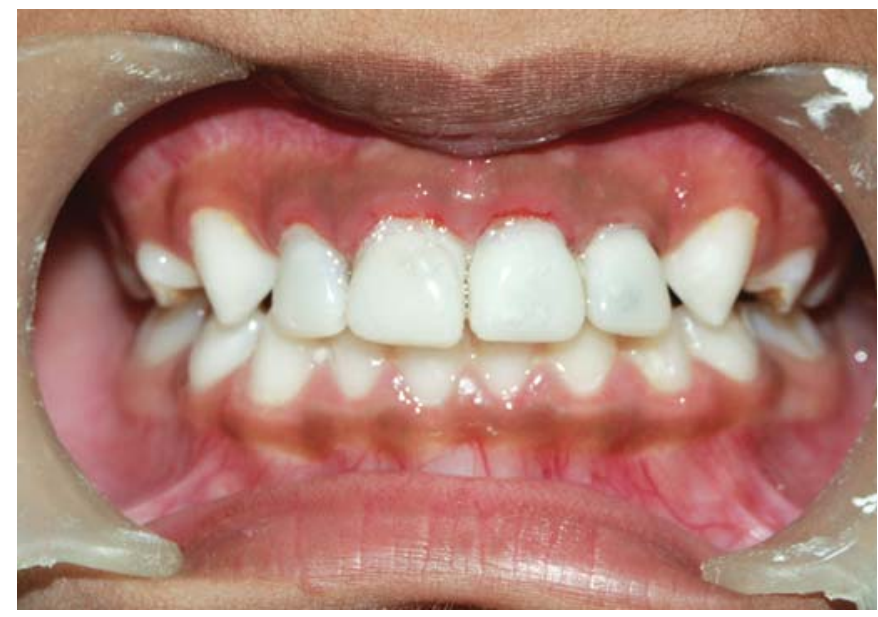

Fig. 6: 51, 52, 61, 62 composite core build up done by strip crowns

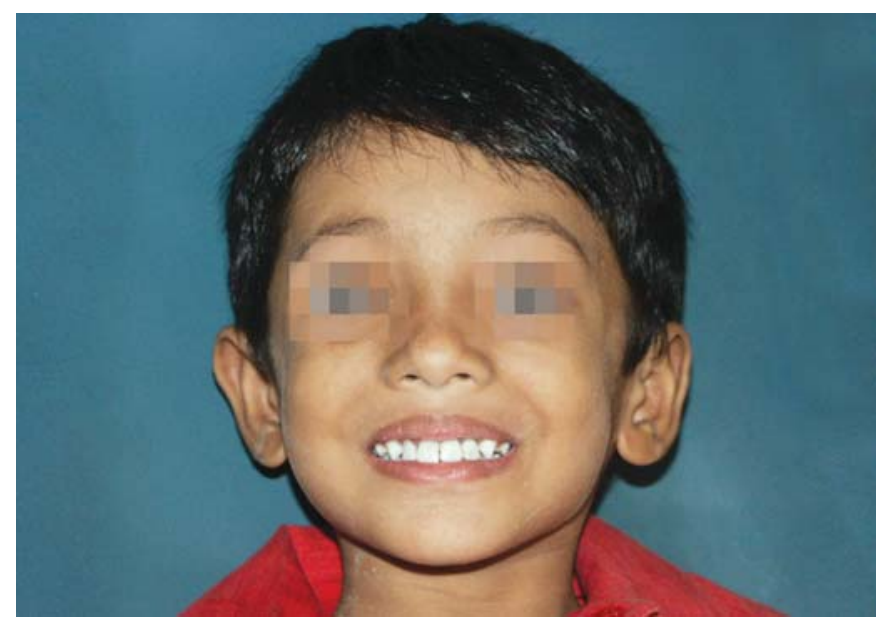

Fig. 7: Postoperative view showing full mouth and psychological rehabilitation

Pulpectomy of $51,61,52,62$ followed by root canal filling with zinc oxide eugenol was carried out along with the other required treatments. A bout $4 \mathrm{~mm}$ of the cement was removed from the coronal end of the root canal and $1 \mathrm{~mm}$ of zinc polycarboxylate cement was placed. A $0.7 \mathrm{~mm}$ stainless steel 
Post Endodontic Restoration of Severely Decayed Primary Dentition: A Challenge to Pediatric Dental Surgeon

orthodontic wire was bent using no. 130 orthodontic pliers into half omega-shape to hold restorative material for core build, and serrations were made on the stainless steel wire to get better mechanical retention. The incisal end of the loop of the wire projected 2 to $3 \mathrm{~mm}$ above the remaining root structure. This provided better mechanical retention and support for the restorative material. Shade sel ection of the composite was made in daylight. A fter polycarboxylate cement set, the canal was prepared to get a space of about $3 \mathrm{~mm}^{7}$

The root canal and the remaining coronal structure was etched with $35 \%$ phosphoric acid for 20 seconds. Then the bonding agent was placed and cured for 20 seconds. Composite restorative material of the selected shade was placed in the canal. The loop was inserted into the canal with composite. The composite was light cured for 40 seconds. A strip crown was used and the crown was reconstructed (Fig. 6). The occlusion was checked and after the removal of any interference, final finishing and polishing of the restoration was performed using soflex tips. ${ }^{6}$

This completed the treatment of the full mouth and psychologically rehabilitation for future treatment (Fig. 7). The patient was advised to come for regular checkup.

\section{DISCUSSION}

Restoring primary anterior teeth that are grossly destructed due to caries is very challenging for the pediatric dentist. There is a high rate of failure, not only because of absence of tooth structure, poor adhesion of bonding agent to primary teeth, limited availability of materials and techniques, but also because the children who require such restorations are among the youngest and least manageable group of patients. To provide shape, function and esthetics in such teeth, use of intracanal retainers is necessary. A fter endodontic treatment and placement of intracanal retainers, the remaining coronal structure can be restored with direct or indirect technique or with single tooth prostheses, such as celluloid strip crowns, stainless steel crowns, metal plastic crowns, porcelain veneers, polycarbonate crowns and acrylic resin crowns etc. ${ }^{8}$

Studies have shown that intracanal retention in primary teeth can be obtained by directly building resin composite posts or preparing an inverted mushroom-shaped undercut in the root canal prior to the build up of the resin. ${ }^{9}$

$M$ ore esthetic option may be the use of a biologic post. The disadvantages of this technique include the need of tooth bank, donor and recipient acceptance and stringent cross-control infection policies. ${ }^{7}$
In this case, custom-made post was used in anterior teeth as M ortada and $\mathrm{K}$ ing, U sha $\mathrm{M}$ et al have shown success with the use of direct composite restoration reinforced with mechanically retained orthodontic wire but other available options, such as threaded posts, nickel-chromium cast posts, preformed and cast metal posts have also been utilized. ${ }^{8}$ However, the whole treatment was technique sensitive and required parent's cooperation. A Iso there was a chance of loss of restoration due to trauma or biting on hard foods, so the parents were advised that the child should avoid hard food. The child was very happy and satisfied regarding all functions of teeth, like mastication, speech, cosmetic function, etc. Restoration was found to be serving well at the 9-month recall and further recall review is needed to check the strength of the posts and resorption of roots.

\section{CONCLUSION}

The direct composite resin restoration using a custom-made post with orthodontic wire used in this case report demonstrated good retention and esthetics. It was easy to perform chair side and benefited the child immensely.

\section{ACKNOWLEDGMENTS}

I would like to thank the entire teaching and nonteaching staff of the Department of Pedodontics and Preventive Dentistry, Ragas Dental College and Hospital, Chennai, and also the patient and her guardian for their continued support during the course of the case.

\section{REFERENCES}

1. Johnson DC. Characteristics and background of children with nursing caries. Pediatric Dent 1982;4:218-24.

2. Ripa LW. Nursing caries: A comprehensive review. Pediatric Dent 1988;10:268-82.

3. Y ui CK, W ei SH. M anagement of rampant caries in children. Quintessence Int 1992;23:159-68.

4. M cdonald, A very, Dean. Dental caries in the child and adolescent. In: D entistry for the child and adolescent (8th ed). Mosby: 2005:209-10.

5. N gan $\mathrm{P}$, Fields $\mathrm{H}$. Orthodontic diagnosis and treatment planning in the primary dentition. ASDC J Dent Child 1995;62:25-33.

6. U sha M, D eepak V, V enkat S, Gargi M. Treatment of severely mutilated incisors: Challenge to the pedodontist. J Indian Soc Pedod Prevent Dent 2007;25:S34-36.

7. M otisuki C, Santos-Pinto L, Giro EM . Restoration of severely decayed primary incisors using indirect composite resin restoration technique. Int J Pediatric Dent 2005;15:282-86.

8. M ortada A, K ing N M . A simplified technique for the restoration of severely mutilated primary anterior teeth. J Clin Pediatric Dent 2004;28:187-92.

9. Rifkin A. Composite post crowns in anterior teeth. J Dent A ssoc S Afr 1983;38:225-27. 